\title{
PROSTHETIC REHABILITATION OF A 3 YEAR OLD CHILD WITH ECTODERMAL DYSPLASIA - A CASE REPORT
}

\section{Aditi Bector $^{1}$, Avninder Kaur ${ }^{2}$, Shivesh Acharya ${ }^{3}$, Sumeet Rajpal ${ }^{4}$, Surabhi Awasthi ${ }^{5}$}

${ }^{1}$ Sr. Lecturer, Department of Pediatric and Preventive Dentistry, Bhojia Dental College and Hospital, Himachal Pradesh, India

${ }^{2}$ Prof. and Head, Department of Pediatric and Preventive Dentistry Bhojia Dental College and Hospital, Himachal Pradesh, India

${ }^{3}$ Reader, Department of Pediatric and Preventive Dentistry, Bhojia Dental College and Hospital, Himachal Pradesh, India

${ }^{4}$ Ex professor, Department of Pediatric and Preventive Dentistry, Bhojia dental college and Hospital, Himachal Pradesh, India

${ }^{5}$ PG Student, Department of Pediatric and Preventive Dentistry, Bhojia Dental College and Hospital, Himachal Pradesh, India

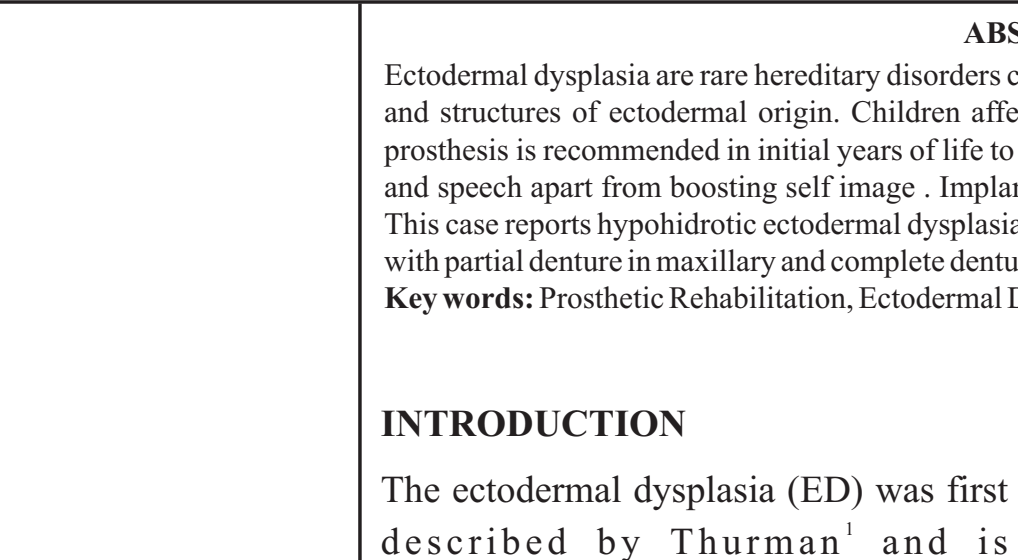
characterized by abnormal development of certain tissues and structures of ectodermal origin such as hair, nails, skin and teeth. ${ }^{2}$ These disorders are relatively rare and occur in 1 in 10,000 to 1 in 100,000 births. ${ }^{3} \quad$ ED can be clinically classified as -:
\end{abstract}

(1) Anhidrotic or hypohidrotic (ChristSiemens-Touraine syndrome): Inherited as an X-linked form, characterized by the classical triad of hypodontia, hypohidrosis and hypotrichosis and characterized by dysmorphic facial features.

(2) Hidrotic (Clouston's syndrome). ${ }^{4}$ Inherited as an autosomal trait, this form of ED usually spares the sweat glands, can affect the teeth, hair and nails.

Corresponding Author: Aditi Bector

E-mail: draditibector@gmail.com Received: $2^{\text {nd }}$ September 2015

Accepted: $27^{\text {th }}$ November 2015 Online: $11^{\text {th }}$ January 2016 in ED patients are to preserve alveolar ridges, early development of perioral musculature, speech and restoring normal facial characteristics. This facilitates normal emotional and psychological development.

\section{Case Report}

A 3 year old boy reported to the Department of Pediatric and Preventive Dentistry, Bhojia Dental College and Hospital, Baddi, with the chief complaint of missing teeth. He was accompanied by his father who gave history of delayed eruption of three teeth in the upper arch at the age of 2 years and non eruption of other primary teeth. Patient had heat intolerance, hyperpyrexia and sweating was absent.

On examination, scalp had sparse and fine hair. The skin over hands was soft, dry and fragile. The reduced lower facial height led to senile facial experience. Hair over eyelashes and 
Table 1 : Different Types of Ectodermal Dysplasia and their Gene Mutations

\begin{tabular}{|c|c|c|}
\hline 1. & $\begin{array}{l}\text { X- linked recessive Hypohidrotic ectodermal } \\
\text { dysplasia (HED) }\end{array}$ & $\begin{array}{l}\text { Xq12- q13. Mutation in gene EDAEDA which } \\
\text { encodes ectodysplasin protein which in turn activates } \\
\text { the NF-kappa B and essential modulator (NEMO), } \\
\text { resulting in conical teeth, sparse hair, anhidrosis or } \\
\text { hypohidrosis, and recurrent bacterial infections. }\end{array}$ \\
\hline 2. & Autosomal dominant hypohidrotic ED & $\begin{array}{l}\text { DL gene, which encodes the EDA (ectodysplasin) } \\
\text { receptor. }\end{array}$ \\
\hline 3. & Autosomal recessive hypohidrotic ED & $\begin{array}{l}\text { EDARADD gene, which encodes } \\
\text { a protein that interacts with the EDA receptor. }\end{array}$ \\
\hline 4. & Hidrotic ED (Clouston syndrome), which & $\begin{array}{l}\text { GJB6, which encodes connexin } 30 \text {, a component of } \\
\text { intercellular gap junctions. }\end{array}$ \\
\hline 5. & $\begin{array}{l}\text { Hay-Wells syndrome (ankyloblepharon filiforme } \\
\text { adnatum), Rapp- Hodgkin syndrome and EEC } \\
\text { (Ectrodactly-ectodermal dysplasia) syndrome. }\end{array}$ & $\begin{array}{l}\text { TP73L (p63) gene, featuring congenital abnormalities } \\
\text { of skin, hair, teeth, nail, eccrine and mucous glands, } \\
\text { as well as cleft deformities. }\end{array}$ \\
\hline \multirow[t]{7}{*}{6.} & a)Palmoplantar keratoderma with deafness & GJB26 gene, which encodes connexin 26 \\
\hline & b)Margarita Island ED & PVRL1 gene, which encodes nectin-1. \\
\hline & c) ED with skin fragility & PKP1 gene, which encodes plakophilin 1 \\
\hline & d) Hypotrichosis with juvenile macular dystrophy & CDH3 gene, which encodes p-cadherin. \\
\hline & e)ADULT syndrome & TP63 gene. \\
\hline & f)Split hand-foot malformation syndrome & TP63 gene. \\
\hline & g)Limb-mammary syndrome & TP63 gene. \\
\hline
\end{tabular}

eyebrows were thin and scanty. Low set ears, everted lips, depressed nasal bridge and frontal bossing were other features in this patient (Figure 1a,b,c). Intelligence level was normal in the child according to his age.

Intra oral examination revealed completely edentulous mandibular arch and maxillary arch with

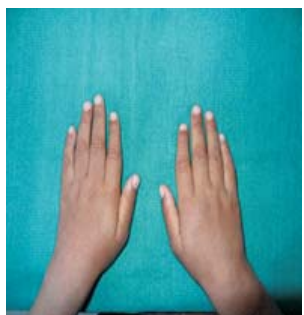

(a)

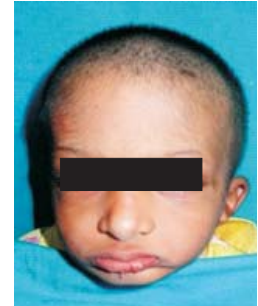

(b)

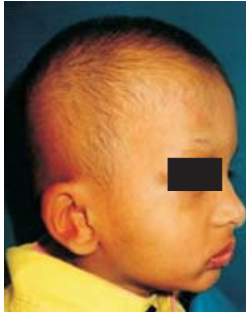

(c)
Figure 1 (a): Showing dry and fragile skin on hands; (b), (c) Showing frontal and lateral view with sparse hair, scanty eyelashes and eyebrows, frontal bossing, depressed nasal bridge, everted lips and low set ears. erupted 51,55 and 65. Due to absence of teeth, alveolar ridges were atrophic and thin (Figure 2a,b). OPG revealed absence of any other primary teeth but maxillary permanent canines and all permanent first molars were present (Figure 3). HED was confirmed on the basis of the clinical features of hypohidrosis, hypotrichosis and hypodontia.

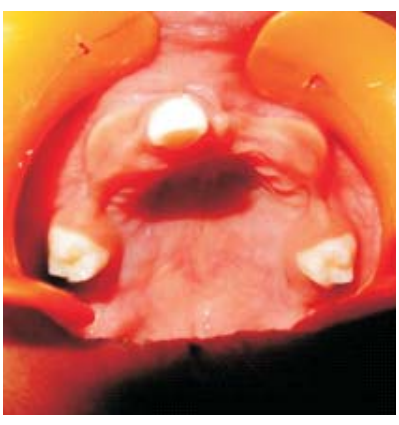

(a)

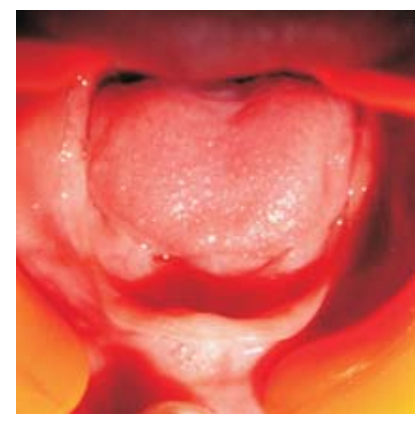

(b)
Figure 2(a) and (b) showing edentulous mandibular arch and maxillary arch with one central incisor and second molars 


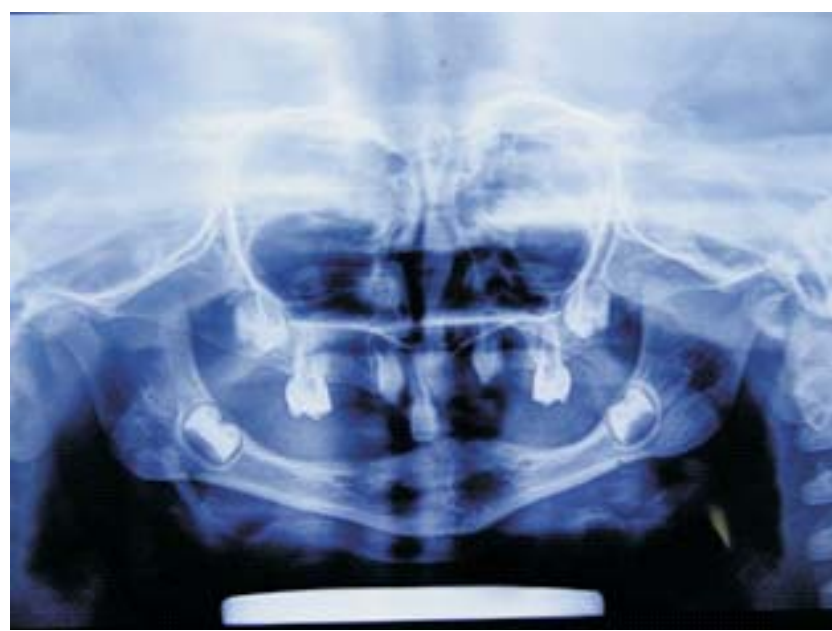

Figure 3: OPG showing presence of permanent canines in maxillary arch and permanent first molars in both arches.

\section{Oral Rehabilitation}

Oral rehabilitation with removable partial denture in upper arch and complete denture in lower arch was planned for the child. This improves maxillomandibular relationship, phonetics, masticatory efficiency and positive self image which is prerequisite for normal psychological development of the child. Young age of patients and atrophic ridge makes ED difficult to be managed prosthodontically.

The child was familiarized with the materials and primary impressions were made using alginate for both upper and lower arches. Sharp and thin ridges were covered with a wax spacer. Acrylic custom trays were prepared and border moulded using green sick compound. Final impressions were made using Zinc Oxide Eugenol impression paste.

Occlusal rims were fabricated, and jaw relations were registered with increased vertical dimension at occlusion to establish better muscle tone and lip support. Acrylic teeth were selected and trimmed to the approximate dimensions of the primary teeth and teeth arrangement was done with bilateral balanced occlusion. Try-in was checked for retention, esthetics and phonetics. Dentures were processed using heat cure fibre reinforced acrylic resin. The processed dentures were finished and polished and inserted (Figure 4a,b). Post insertion instructions on denture wear, functions of speech, mastication, hygiene and maintenance were given. The facial profile and

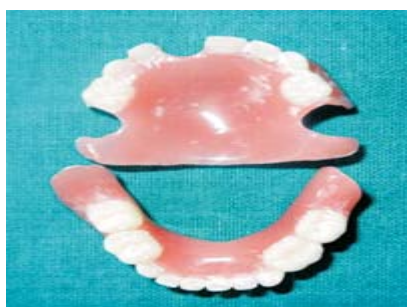

Figure 4a: Denture fabricated

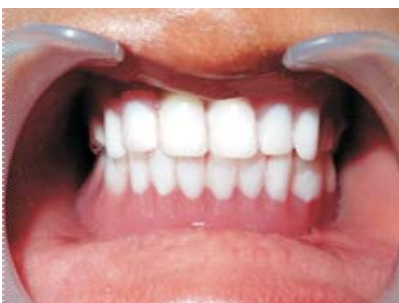

Figure 4b: Denture inserted expressions improved significantly with complete dentures (Figure 5a,b). Recall appointments were scheduled after 24 hours, 1 week, 4 weeks and 6 weeks.

The patient was examined after 24 hours. Retention and stabilization of the dentures were

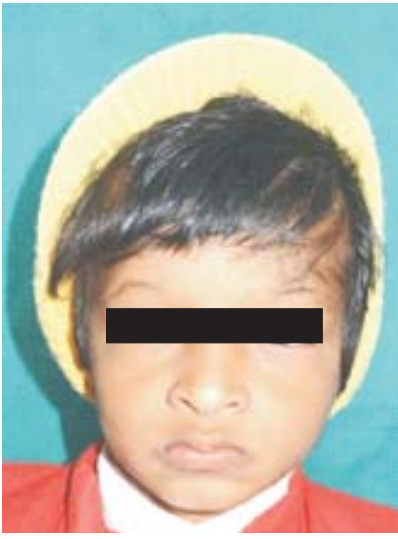

(a)

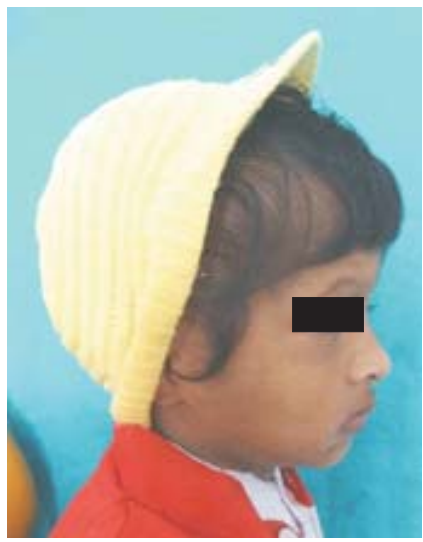

(b)
Figure 5(a) (b): Showing frontal and lateral view post insertion of denture

clinically acceptable. Discomfort areas were relieved. Instructions were given to the parents for home care of the denture and replacement by new ones as growth occurs. The patient had no discomfort and seemed to be adapting well on the following weekly visits.

\section{DISCUSSION}

A multidisciplinary approach and knowledge of behaviour management is the prerequisite for rehabilitation of a child with Ectodermal Dysplasia. Prosthetic rehabilitation in children with HED depends on the degree of anodontia. In patients with partial anodontia, removable/fixed partial dentures and overdentures may be considered ${ }^{8}$ according to number of teeth present. Oral rehabilitation at an early age improves perioral muscle tonicity, delays alveolar bone 
resorption associated with the absence of teeth. ${ }^{9}$ The initial dentures at preschool stage helps in better adaptation by the child. As the child grows, the denture will have to be relined and replaced, in primary, mixed and permanent dentition till the growth is complete. If we do not rehabilitate the oral function, this will lead to class III malocclusion, which is caused by rotation of mandible anteriorly and represents as an upward and forward displacement of the chin, with a reduction in the lower facial height. ${ }^{1}$

Fixed prosthesis are rarely used exclusively in the treatment of ED because of the presence of least number of teeth and if prosthesis cross the midline, rigid connectors may cause interference with jaw growth. ${ }^{4}$

Osseointegrated implants are also an alternative to removable prosthesis. Overdentures with implants have an advantage of stability and retention but the dental implants in young children may get submerged when placed in development years. ${ }^{10}$ Infraocclusion may also result due to growth of the adjacent natural teeth ${ }^{11}$ and the dramatic growth changes of maxilla and mandible are not conducive to the maintenance of implants. ${ }^{12}$ This approach should be postponed until 13 years of age because of possible implant movement caused by jaw growth. ${ }^{13}$ The use of implants in the anterior mandible may be routinely recommended in young patients ${ }^{14}$ and can be placed to support an overdenture from the age of around 6 years, when the median suture of the mandible is closed. ${ }^{15}$ As the lateral growth of the anterior mandible is usually completed by 3 years of age, implant placement can be considered if anodontia exists in this area. Soft tissue implants can be considered as an alternative.

Ectodermal dysplasia patients need interdisciplinary approach for their special needs, which includes prosthesis at an early age with relining and replacement as growth occurs.

\section{CONCLUSION}

Early prosthetic treatment in cases of Ectodermal dysplasia improves physical and psychological growth of the child. It is recommended to rehabilitate the patient with dentures as early as preschool age and subsequent transition to fixed prosthesis/implants once the growth is complete.

\section{REFERENCES}

1. Tarjan I, Gabris K and Rozsa N. Prosthetic treatment of patients with ectodermal dysplasia: A clinical report. J. Prosthet Dent 2005;93:419-424

2. Kramer F, Baethge C, Tschernitschek H. Implants in children with ectodermal dysplasia: A case report and literature Review. Clin Oral Impl Res 2007;18:140-6

3. Priolo M, Silengo M, Lerone M, Ravazzolo R. Ectodermal dysplasia: Not only'skin' deep. Clin Genet 2000;58:415-30

4. Gupta S, Tyagi P. Prosthodontic management of anhidrotic ectodermal dysplasia. Indian J Dent Res 2011;22:348-51

5. Chang TT, Behsad R, Brodell RT, Gilliam AC. A male infant with anhidrotic ectodermal dysplasia/immunodeficiency accompanied by incontinentia pigmenti and a mutation in the NEMO pathway. J Am Acad Deramatol 2008;58:316-20

6. Bal E, Baala L, Cluzeau C, El Kerch F, Ouldim K, Hadj- Rabia S. Autosomal dominant anhidrotic ectodermal dysplasias at the EDARADD locus. Hum Mutat 2007;28:703-9

7. Available from: http://emedicine.medscape.com/article/1110595overview

8. Vieira KA, Teixeiva MS, Guirado CG, Cariaro MB. Prosthodontic treatment of with complete anodontia: case report. Quintessence Int 2007;38:75-80

9. Acikgoz A, Kademoglu O, Elekdag-Turk S and Karagoz F. Hypohidrotic ectodermal dysplasia with true anodontia of the primary dentition. Quintessence Int 2007;38:853-85

10. Guckes A, Scurria M, McCarthy G, Brahim J. Prospective clinical trial of dental implants in persons with ectodermal dysplasia. J Prosthet Dent 2002;88:21-5

11. Celar AG, Durstberger G and Zauza K. Use of an individual traction prosthesis and distraction osteogenesis to reposition osseointegrated implants in a juvenile with ectodermal dysplasia: a clinical report. J Prosthet Dent 2002;87:145-148 
12. Shaw WC. Problem of accuracy and reliabiltiy in cephalometric studies with implants in infants with cleft lip and palate. Br J Orthod 1977;4:93-100

13. Guckes AD, Brahim JS, McCarthy GR, Rudy SF and Cooper LF. Using endosseous dental implants for patients with ectodermal dysplasia. JADA 1939;122:59-62
14. Guckes AD, Roberts MW, McCarthy GR. Pattern of permanent teeth present in individuals with ectodermal dysplasia and severe hypodontia suggests treatment with dental implants. Pediatr Dent 1998; 20:278-80

15. Bergendal B, Koch G, Karol J, Wanndahl G. Consensus Conference on Ectodermal Dysplasia with special reference to Dental Treatment. Stockholm, Sweden: Forlagshuset Gothia AB; 1998

\section{Source of Support: Nil, Conflict of Interest: None Declared}

